\title{
REFLEXIONES SOBRE LA SOCIEDAD IBÉRICA Y EL REGISTRO ARQUEOLÓGICO FUNERARIO ${ }^{1}$
}

\author{
POR
}

\author{
JUAN A. SANTOS VELASCO
}

Departamento de Historia Antigua y Arqueologia, CEH, CSIC.

\section{RESUMEN}

Los últimos datos arqueológicos de las necrópolis ibéricas sirven de base para apoyar la tesis de que la sociedad ibérica prerromana, del sureste peninsular, es una sociedad de clases en la que se hace necesario un mecanismo de integración de tipo estatal: en este caso con un fuerte componente aristocrático.

\section{SUMMARY}

Our last archaeological data concerning lberian cemeteries serve as a basis to support the idea that Pre-roman Iberian society (of the Southeast of the Peninsula) is a class society in wich a state mechanism of integration is made necessary, being therefore related to a strong aristocratic component.

«El estado... está destinado a reglamentar el funcionamiento de la sociedad de tal manera que éste permita la constante reproducción de las condiciones económicas, juridico-politicas e ideológicas, que aseguren una reproducción de las relaciones de dominación de una clase sobre las demás" (Harnecker, M., 1973, 121).

En este párrafo encontramos el núcleo del problema sobre qué es el estado y, por tanto, cómo reconocerlo en las comunidades protohistóricas objeto de nuestro análisis. Las preguntas que hemos de contestar son si en el seno de aquellas sociedades se dan las relaciones de clase, y cómo atestiguarlas a partir del registro arqueológico. En las páginas siguientes se trata de abordar este tema, en el caso concreto del mundo ibérico del sureste peninsular, entendido éste en un sentido amplio.
Cuando hace unos años publicaba el estudio sociológico de la necrópolis de El Cigarralejo (Santos Velasco, J.A., 1989) establecia tres criterios para intentar acercarnos a la estructura social ibérica de la cuenca del Segura, entre los siglos vi-II a.C.

a) Los monumentos funerarios.

b) Las cerámicas de importación.

c) El armamento.

a) La mayoria de los monumentos funerarios de la región corresponden a la fase ibérica antigua (550/525-450/425 a.C.), documentándose una destrucción de los mismos ya a principios del siglo $\mathrm{v}$ a.C. (Ruano, E., 1987, 207), momento a partir del cual la arquitectura funeraria monumental va desapareciendo.

b) Frente a los vasos de importación aislados, documentados en la fase antigua, y que parecen responder a un intercambio de dones, entre miembros eminentes de las comunidades indigenas y agentes coloniales, más que a un tráfico sistemático; en la fase plena, el volumen de importaciones es sustan-

\footnotetext{
'Quiero dedicar este trabajo al Dr. Emeterio Cuadrado, quien en su momento puso a mi completa disposición los datos de la necrópolis de El Cigarralejo, que se convirtieron en el eje vertebrador del capitulo dedicado a las necrópolis ibéricas de mi tesis doctoral y, más tarde, en un articulo aparecido, en esta misma revista, en el año 1989. Los nuevos datos proporcionados por trabajos de campo hacen posible incidir, pasados cuatro años, en la denominada "Arqueologia de la Muerte», en época ibérica, con nuevas propuestas, cuyas bases no se hubieran podido levantar, en su momento, sin la enorme cantidad y calidad de datos procedentes de la necrópolis murciana de Mula, conseguidos gracias al tesón y buen hacer del Dr. Cuadrado, de cuya figura tenemos, todos los que nos dedicamos al análisis de las necrópolis ibéricas, mucho que aprender.
} 
cialmente mayor, repartiéndose entre un sector de la población minoritario, pero de cierta amplitud relativa (el 30 por 100 de las tumbas de El Cigarralejo, o el 17 por 100 de las de Baza contienen cerámicas griegas; Santos Velasco, J. A., 1989, 83).

c) Por su parte, las armas en general, y las espadas en particular, son más escasas en las necrópolis antiguas (ponia entonces los ejemplos de El Molar, La Solivella y La Bobadilla; Santos Velasco, J. A., 1989, 88), que en las necropolis de la fase plena. Recientes excavaciones parecen confirmar esta hipótesis. En Los Villares (Albacete), la panoplia no se documenta en el siglo $v$ a.C. salvo excepciones (Blánquez, J., 1992, 256). Y en Cabezo Lucero (Alicante) la mitad de las 14 tumbas o puntos, datables en el siglo $v$ a.C. poseen :rmas, mientras que más de la mitad de los 64 puntos del siglo IV a.C. documentan armamento ?.

Habria un cuarto criterio, que aparece de forma implícita en autores como Almagro Gorbea. En opinión de estos investigadores, el espacio funerario y sagrado de las necrópolis antiguas está reservado a muy pocos individuos, e incluso lo forman únicamente enterramientos aislados, como ocurre con las tumbas monumentales de Pozo Moro (Albacete) y de El Prado (Jumilla, Murcia). Sin embargo, desde fines del siglo v a.C. la ocupación de aquel espacio se amplia, apareciendo las grandes necrópolis de la Fase Plena, formadas por centenares de tumbas (El Cigarralejo, La Albufereta, El Cabecico del Tesoro, Baza). Hecho que parece tener también confirmación en recientes estudios, como el de Cabezo Lucero, donde tan sólo 14 sepulturas se fechan en el siglo v a.C., mientras 71 lo hacen en el siglo iv a.C. ${ }^{3}$.

En 1989 propuse que estos cambios, que se atestiguan en el mundo ibérico de la cuenca del Segura, respondian al tránsito de una organización tribal (jefatura compleja) a una sociedad de clases de carácter aristocrático. Ya que aquellos fenómenos se pueden interpretar como un contraste muy marcado entre uno o unos pocos personajes de élite que, en la fase antigua, se entierran bajo monumentos, acceden a los escasísimos bienes exóticos de origen greco-púnico, y tienen derecho a portar armas; frente al resto de una comunidad que ni accede al espacio funerario, ni al mercado de importaciones, ni al uso de armas. A falta de más datos y a título de hipótesis, nos hallaríamos ante unos grupos en los cuales emerge un miembro, como un jefe, frente a un conjunto social más o menos homogéneo. Por el contrario, du-

\footnotetext{
${ }^{2}$ Intervención oral de J. Uroz, Actas del Congreso de Arqueología Ibérica: las necrópolis, 1992, 656.

${ }^{3}$ Intervención oral de J. Uroz en el Congreso de Arqueologia Ibérica: las necrópolis, 1992, 656.
}

rante la fase plena, el acceso de más individuos a los espacios funerarios, al mercado de cerámicas de importación, y al derecho a llevar armas son reflejo de una sociedad mas estructurada y compleja, donde ya no se da una tajante dicotomia individuo ( ¿jefe?) / resto de la población. sino una dicotomia grupo aristocrático dominante y, tal vez, sus clientes/resto de la población dependiente ${ }^{4}$.

Las diferencias cuantitativas, en el material arqueológico, entre las fases antigua y plena, tomadas en su conjunto, tienen tal relieve que se convierten en diferencias cualitativas, exponentes del cambio cultural y social que se da entre ambos períodos. Cambio que se resume en el surgimiento y consolidación de una aristocracia armada dominante que se configura, en la fase plena $(450-425 / 325$ a.C. aprox.), como clase social dominante, con todas las connotaciones económicas y políticas que conlleva este término. Contamos con más datos, procedentes del registro funerario, que nos ayudan a argumentar, más allá, cómo se define esa sociedad de clases.

Desde fines del siglo vı a.C. han aparecido aquellos miembros eminentes de la sociedad, que se entierran bajo tumbas monumentales y que desde, al menos, los comienzos del siglo $v$ a.C. se representan a caballo, símbolo de su estatus. Asi lo demuestran los monumentos de Porcuna (Negueruela, I., 1990) y el jinete antiguo de Los Villares, de 490 a.C. (Blánquez, J., 1992, 253). Son el precedente inmediato de la aristocracia que se afirma en el período siguiente, la fase plena, cuando se documentan las llamadas "tumbas principescas», en cuyos ajuares aparecen bocados de caballo ${ }^{5}$. Su constatación es paralela a la de lo que podemos considerar un séquito de jinetes, de equites, como se advierte en El Cigarralejo (Santos Velasco, J. A., 1989, 92), El Cabecico del Tesoro (tumbas 187 y 292 ver Que-

\footnotetext{
4 Para definir estas circunstancias empleé entonces (Santos Velasco, J. A., 1989) la palabra, entre comillas, "democratizaciónn de los espacios funerarios y de los mercados de objetos de importación. Con el tiempo se ha hecho evidente lo desafortunado de aquel término que, en lugar de aclarar, ha servido para sembrar, en ocasiones, la confusión. No se trata de que en el siglo iv a.C. la sociedad ibérica tenga un carácter más igualitario, sino de que se ha ampliado el cuerpo social de los linajes dominantes, que están representados en las necrópolis que, además, hacen participes de su posición privilegiada a sus vinculados y clientes. En la misma dirección que la propuesta de la existencia de una cierta isonomia entre los diferentes linajes aristocráticos (Ruiz, A. y Molinos, M., 1993, 264).

'Tumbas 200 y 277 de El Cigarralejo (Cuadrado, E., 1987). En el Cabecico del Tesoro las tumbas 27 (la más rica entre las del siglo III a.C.) y 400 (la más rica entre las del siglo IV a.C.. ver Sánchez Meseguer y Quesada, 1992). En Coimbra del Barranco Ancho, la Tumba principesca 70, en cuyo ajuar se documenta una espuela (Page, V. et al., 1987, 42).
} 
sada, 1989)", Coimbra del Barranco Ancho (tumba $55)^{7}$ y Baza (tumbas 151,166 y 178 . Ruiz, A. et al., 1992. 416). En el siglo Iv a.C., el princeps no se halla aislado, sino apoyado en un grupo secundario de "caballeros», que forman parte o están vinculados a la clase dominante por lazos de dependencia.

Por otra parte, en el conjunto mayoritario de las tumbas del siglo IV a.C. la extrema complejidad de los ajuares funerarios, y de las acumulaciones de elementos ricos en los mismos, reflejan una sociedad muy compleja y estructurada en distintos niveles y posibilidades de acceso y acumulación de la riqueza. Es probable que, por entonces, haya surgido un pequeño segmento social intermedio, formado por artesanos y comerciantes enriquecidos, a juzgar por ciertos datos arqueológicos (Santos Velasco, J. A., 1989).

A tenor de lo expuesto parece justificado proponer que la Fase Plena, momento de apogeo de la cultura ibérica, se asienta sobre una estructura social compleja, que ya podemos considerar de clase. De nuevo, el registro funerario nos ayuda a completar esta hipótesis.

\section{¿QUIÉN SE ENTIERRA EN LAS NECRÓPOLIS? DESARROLLO DE UNA SOCIEDAD GENTILICIA}

El hecho de que en las necrópolis ibéricas no esté representada toda la población es algo unánimemente aceptado ${ }^{8}$. No obstante, es todavía pronto para decidir si aquéllos que tienen derecho a usar ese espacio sagrado son sólo los propietarios, como sugieren algunos autores (Plácido, D., et al., 1991, 193) entre otras cosas, y como señalan esos mismos investigadores, porque desconocemos qué tipo de propiedad dominaba entre aquellos pueblos ${ }^{9}$. Dato im-

\footnotetext{
- La tumba 187 tiene un valor de 29,5 y contiene armas y espuelas. Por su parte, la 292 documenta armas y bocados de caballo, y con un valoración global del ajuar de 14,5 supera también el valor medio de los ajuares de la necrópolis, establecido por Quesada $(1989,178)$ en 8,5 .

' Su rico ajuar, fechado en el siglo II a.C., contiene bocados de caballo y un adorno de frontalera de plata (ver Page, V. et al, 1987, 42).

"Ver las páginas de debate del Congreso de Arqueologia Ibérica: las necrópolis, Madrid, 1992.

* Sobre la cuestión de la propiedad tenemos algunos datos aislados que sugieren algunas propuestas. La destrucción de armas y cerámicas, en las tumbas, significa la propiedad personal del objeto (Bartoloni, G., et al., 1982, 265). Esto al menos nos aproxima al tema de la propiedad privada de útiles de uso personal. Aunque, el problema esencial es cuál es el tipo de propiedad de los Medios de Producción, del que pudiera ser evidencia indirecta el proceso de acumulación de riqueza, en los ajuares principescos (d'Agostino, B, 1992; ver también Santos Velasco, 1989, 93-94).
}

prescindible para conocer muchas cuestiones, entre otras, cuáles eran las Relaciones Sociales de Producción, algo que es del todo necesario para comprender los fundamentos socio-económicos de la cultura ibérica (Plácido, D. et al., 1991, 190).

De cualquier modo, aunque no sepamos con exactitud quiénes constituian aquellos grupos que se enterraban en las necrópolis que conocemos, en este hecho encontramos la primera gran diferenciación social, que se establece en el seno de las comunidades ibéricas: los grupos dominantes y sus vinculados, tal vez clientes, que tienen derecho al uso de aquel espacio sagrado; y los grupos dependientes o dominados, que no dejan constancia en el registro arqueológico funerario. Si ésta es la situación estariamos ante la primera evidencia de que el mundo ibérico se estructura como una sociedad de clases, puesto que si se tratara de una sociedad preclasista. basada en relaciones de parentesco, las exclusiones se establecerían por grupos de edad y sexo, lo que no parece ser nuestro caso al menos en la fase plena ${ }^{11}$.

Ahora bien, la afirmación de que en ese periodo. en las necrópolis, sólo se representa la clase dominante habría que matizarla, pues junto a las ricas tumbas de los miembros de élite encontramos un alto porcentaje de sepulcros que podemos considerar "pobres», en El Cabecico del Tesoro (Quesada, F., 1987-88), Baza (Ruiz, A. et al., 1992), Coimbra del Barranco Ancho (García Cano, J.M., 1992), Castellones de Ceal (Chapa, T. y Pereira, J., 1992) y El Cigarralejo (Santos Velasco, 1989). El problema es saber a qué sector social pertenecen estas tumbas y, hoy por hoy, no se puede dar una respuesta segura.

Aquellas tumbas «pobres» podrían corresponder:

1) A algunos miembros de las clases dependientes.

2) A los miembros menos favorecidos de los grupos dominantes, o linajes secundarios, que adquieren el derecho de ser enterrados en el espacio sacro de las necrópolis por sus lazos, más o menos cercanos, con los linajes de la élite.

3) $\mathrm{A}$ individuos o linajes que han establecido relaciones de dependencia militar o religiosa, con miembros de la clase dominante.

4) A grupos de edad/sexo, como es el caso de la necrópolis alicantina de Cabezo Lucero (Aranegui, C. et al., 1992). Alli los análisis de laboratorio han dado como resultado que las tumbas más ricas

\footnotetext{
${ }^{10}$ Por los resultados de los análisis antropológicos llevados a cabo en Pozo Moro, Los Villares y Cabezo Lucero, sabemos que adultos, niños, hombres y mujeres ocupan las necrópolis, acompañándose de ajuares que podemos considerar tanto uricos", como "pobres".
} 
pertenecen a individuos masculinos adultos, siendo mayoritariamente menos ricas las tumbas femeninas e infantiles. En una primera lectura, esto nos estaria indicando que los grupos de edad y sexo son los socialmente dominantes, en este lugar, y nos hallariamos, por tanto, en un estadio social preclasista.

No obstante, habriamos de tener en cuenta varias circunstancias.

a) La necrópolis de Cabezo Lucero es muy singular. En el periodo comprendido entre 425-375 a.C. el 37 por 100 de las tumbas tienen armas. Cifra elevada si la contrastamos con las de otros yacimientos, aunque dentro de unos parámetros regulares: El Cigarralejo (31\%), Cabecico del Tesoro (21\%), Los Nietos (38\%), Coimbra del Barranco Ancho (24\%. ver Sánchez Meseguer, F. y Quesada, F., 1992, 370). Pero, en el periodo siguiente (375-300 a.C.), las armas están presentes en un $60 \%$ de las sepulturas, y la cerámica ática en el $74 \%$. La riqueza de los ajuares con cerámicas griegas es tal que sólo se puede calificar de espectacular y, de nuevo, de singular. La interpretación de necrópolis especializada en un sector militar dominante, dada por sus excavadores (Aranegui, C., et al., 1992, 178), parece lo más acertado.

b) El hecho de que armas y cerámicas áticas subrayen, en esta necrópolis, la distinta posición social de los hombres adultos, pudiera tener otras explicaciones, aparte de la ya señalada singularidad del yacimiento; dado que el problema no es que continúen existiendo las relaciones parentales, como vinculo de cohesión. La cuestión es si éstas son, o no, las relaciones sociales dominantes, en el siglo IV a.C.. De hecho, en todas las sociedades precapitalistas el parentesco constituye un lazo social básico, pues es el nacimiento en el seno de los linajes dominantes o dominados, lo que determina la pertenencia de los individuos a una u otra clase. Una explicación alternativa para esta necrópolis alicantina pudiera ser que se está evidenciando la importancia de la continuidad de los vínculos de parentesco, en una sociedad de clases de carácter gentilicio ".

También hemos de tener en cuenta los datos procedentes de otros yacimientos. En la necrópolis de Los Villares (Albacete, Blánquez, J., 1990) no se

\footnotetext{
"Según Godelièr (en Nocete, F., 1989, 12), "las relaciones de parentesco pueden seguir existiendo en sociedades de clase y estatales... el problema concreto del paso a las sociedades de clase y al estado, se ciñe en saber en qué condiciones las relaciones que camufla el parentesco segmentario, y que dominan en las sociedades sin clases, dejan de desempeñar el rol dominante de todas las fuerzas de la sociedad».
}

desprende que haya un vínculo directo entre la riqueza del ajuar y el binomio sexo/edad.

Por otra parte, sabemos que existen ricas tumbas femeninas, como la de la Dama de Baza (Presedo, F, 1982), de una mujer joven, de alto rango, que además se enterró con una panoplia completa de guerrero, simbolo de su pertenencia a la clase dominante; o la tumba 22 b de Los Villares (Blánquez. J., 1990, 434), que contiene dos probables abrazaderas de lo que pudo ser un puñal o espada corta, y que se data en la segunda mitad del siglo vı a.C. También contamos con ricas tumbas infantiles, con armas, como la tumba 36 de Los Villares (500-450 a.C., Blánquez, 1990, 180); o la 91 de Cabezo Lucero, que se fecha entre 450-425 a.C. (Aranegui, C., et al, 1993).

En estos casos lo que se nos está poniendo en evidencia es la relevancia que ha cobrado la pertenencia a un linaje dominante y no a un grupo de edad o sexo. Términos que podemos interpretar como la superación del parentesco y el surgimiento de un nuevo tipo de relaciones sociales más complejas: las de clase. En este sentido, si la circunstancia básica que concurre en la aparición del estado es la existencia de una sociedad clasista, pues: "cuando una sociedad de clases está consolidada también lo está el estado" (Bromlei y Pershits, 1985, 62); en el mundo ibérico, al menos en su Fase Plena, nos hallamos ante ello.

En la fase antigua es difícil discernir si también estamos ante una estructura social de clases, pues los datos que tenemos, tanto de aquel periodo, como del precedente, son muy pobres. Este es un punto de discusión sugerente, pero habrá que esperar a que más excavaciones nos proporcionen datos sobre el mundo funerario, entre los siglos vill-vı a.C.. No obstante, no podemos descartar que ya en la fase antigua existieran clases sociales, como nos sugieren datos, ahora, aislados, como las citadas tumbas 22 b (rica mujer adulta) y 36 (tumba infantil con armas) de Los Villares; o la T-91 de Cabezo Lucero (rica tumba infantil con armas), fechada entre 450425 a.C., un momento inicial, o de tránsito a la fase plena.

$\mathrm{Si}$ a esto añadimos que las transformaciones sociales son más rápidas que las que se aprecian, a través de la cultura material, en la arqueología de las necrópolis, debido a las profundas raices que tienen los componentes ideológicos de la muerte, en cualquier sociedad (Morris, I., 1980, 209), pudieramos estar desde fines o mediados del siglo vi a.C. ante una sociedad clasista, en el mundo ibérico del Sureste, aunque ésta no se represente como tal en los ajuares funerarios, más que en casos aislados. 
No sería esta circunstancia un ejemplo singular en el Mediterráneo. En un ambiente semejante al nuestro, el villanoviano, tanto Torelli (1981), como Bartoloni (1989) son de la opinión de que la igualdad de los contenidos de los ajuares funerarios del ViIlanoviano Inicial es más formal, que sustancial. Las comunidades villanovianas, en la primera mitad del siglo Ix a.C., pudieron presentar diferencias netas de riqueza, entre sus miembros, pero éstas no eran representadas a través de los ajuares, debido a condicionamientos de carácter ideológico. ¿Seria éste también el caso del Periodo Ibérico Antiguo? ${ }^{2}$.

A este respecto, no podemos dejar de tener en cuenta que, en la cultura ibérica, nos hallamos ante un proceso de transición, de un modo de producción comunitario, a otro de clase, en el que se darian situaciones intermedias, no claramente definidas.

Pero las ricas tumbas femeninas e infantiles no sólo nos acercan a la cuestión de la división de la sociedad en linajes dominantes y dominados, dicho de otra manera en clases antagónicas, sino que también, implicitamente, nos informan sobre la reproducción del sistema social. Reproducción que se sustenta sobre dos pilares: la propiedad y la herencia.

Ya Nicolini apuntó que el oro no se documentaba, en las necrópolis ibéricas, salvo en raras ocasiones y nunca en abundancia, porque no era un mero simbolo de estatus, sino que su uso continuado cumplia un papel esencial en la transmisión hereditaria de bienes de carácter familiar. Chapa Brunet y Pereira (1991), abundando en esa idea, son de la opinión de que se evitaba amortizar piezas de oro y plata, en las tumbas, porque la estructura social se fundamentaba más en la pertenencia a un linaje, que en la competición personal. La élite ibérica asentaría su poder en el control de los medios de producción (ganado, tierras, comercio y minas) y los lazos familiares asegurarian la transmisión hereditaria del poder $y$, por tanto, de la reproducción de la élite como grupo diferenciado. Así se comprenderia la profusión de objetos caros (pero sustituibles) en las sepulturas, y la ausencia de otros, como el oro, cuyo valor real predominaría sobre el simbólico, haciéndolo imprescindible para mantener el nivel de riqueza de los descendientes.

\footnotetext{
${ }^{12}$ En todos mis trabajos anteriores señalo que la sociedad clasista se define en la fase plena,y que el periodo antiguo podemos caracterizarlo como una organizacion tribal avanzada. Por el momento y en el sureste, es más prudente continuar con esa hipótesis. No obstante, nuevos datos están evidenciando situaciones que nos hablan ya para la fase antigua de una posible sociedad de clases, y este hecho es necesario exponerlo, a la espera de que una documentación más rica confirme o refute esta otra hipótesis.
}

Estariamos ante una aristocracia hereditaria que transmite su fortuna de padres a hijos, facilitando asi la acumulación de riquezas en manos de ciertas familias, lo que no sólo consolidaría la diferenciación entre linajes ricos y pobres, sino la reproducción de los linajes dominantes, a lo largo del tiempo (Engels, F., 1884, 1980, 121); lo que redunda sobre el carácter gentilicio de la sociedad ibérica.

Sobre este punto, contamos con otros datos, de nuevo del registro funerario. Me refiero a los monumentos y necrópolis de Pozo Moro y Porcuna, vestigios ambos de formas de organización gentilicia. Ello se infiere por una circunstancia: en torno a los monumentos se organiza, tras un hiatus, una necrópolis de la fase plena.

En el caso de Pozo Moro, un pequeño cementerio se articula alrededor de la torre, a partir de 450 a.C.. El grupo que se entierra en ese momento rememora, en el gran monumento turriforme, a un individuo, a mitad de camino entre lo heróico y lo sacro ${ }^{13}$; a un jefe o a un monarca, fundador del linaje dominante que es sepultado más tarde. En opinión de Almagro, los nuevos enterrados guardarían vinculos de parentesco o de filiación social, con el personaje del monumento $(1983,280)$.

En Porcuna, este fenómeno se da dos veces consecutivas. Existe una necrópolis de época orientalizante (siglos vil-vı a.C.), hay un hiatus, se levanta y destruye el monumento, hay un segundo hiatus, y se documenta la necrópolis del siglo iv a.C.. La comunidad de Obulco parece guardar un recuerdo histórico/mítico con aquel lugar, generación tras generación, a lo largo de cuatro siglos. Allí se enterraron los antepasados; y los grupos que se van enterrando con posterioridad descenderian de forma real o ficticia (mitica), de un antiguo grupo dominante, que legitima a los nuevos grupos dominantes, su poder, y formas de control social, con el uso del terreno sagrado del cementerio ${ }^{14}$.

Contamos con un caso semejante, pero esta vez asociando poblado y necrópolis, en El Oral y El Molar (Alicante), al que no se puede dejar de hacer mención, tras sus recientes publicaciones. El Molar es un pequeño yacimiento (del que se conocen alrededor de 30 sepulturas), fundamentalmente de la Fase Ibérica Antigua, cuyos materiales, recuperados en una vieja excavación, han sido reestudiados, y permiten fechar el lugar entre 580-375 a.C. aproximadamente; desde el final del periodo orientalizante, a

\footnotetext{
${ }^{13}$ Aspecto éste que se deduce de la iconografia de los relieves de la torre.

14 Saxe, 1970, Social dimensions of mortuary practices, en Arnold, 1991, 439.
} 
un momento central de la fase ibérica plena. Los materiales muestran una gran riqueza: escultura monumental, copas de Siana, y otros vasos griegos (cráteras, ánforas), escarabeos, aribalos de fayenza, broches de cinturón, etc. (Monraval, M., 1992). Todo lo que sugiere la interpretación del yacimiento como un cementerio de la élite emergente, en los inicios del siglo via.C., que perpetúa su ocupación hasta el periodo de consolidación de las aristocracias locales, en la primera mitad del siglo Iv a.C.

Esta necrópolis corresponde al poblado de El Oral, de 1 ha. de extensión, y amurallado, cuya excavación es del máximo interés, pues aporta nuevos datos a la visión que teníamos del Bajo Segura, en Epoca Antigua. En él se han documentado varias unidades domésticas, entre las que sobresale, por la calidad de los hallazgos la IIIL (con fragmentos de huevos de avestruz, asador y olpe de bronce, y fragmentos de cerámicas griegas). Sus excavadores datan este hábitat entre fines del siglo vı a.C. y 450 a.C. aproximadamente, momento en el que se abandona y su población se translada a la Escuera (Abad, L. y Sala, F., 1993, 91 y ss.).

A la vista, tanto de los ajuares domésticos, como de los funerarios, surge la pregunta de si nos hallamos ante el asentamiento y necrópolis de un linaje dominante de la fase antigua, que hundiria sus raices en el período orientalizante, y que utiliza el espacio sacro de El Molar, en exclusiva, a lo largo de varias generaciones. Incluso, cuando se ha abandonado el poblado de El Oral, a mediados del siglo v a.C., los descendientes y miembros de aquel linaje de elite continuarian sepultándose allí donde lo hicieron sus antepasados hasta un momento comprendido entre 375-350 a.C. Hipótesis que se enmarcaria en el seno de una sociedad de carácter gentilicio y con fuertes vínculos de dependencia. Estos últimos son otro dato más a tener en cuenta, a propósito de la complejidad social del sureste ibérico. Por las fuentes escritas sabemos que existen la devotio y la fides, que crean situaciones de dependencia militar, al margen del parentesco (Prieto Arciniega, P. $1978,142)$. En el registro arqueológico no contamos con una documentación, por mínima que sea, que nos permita advertir la existencia y articulación de las formas de dependencia, a no ser aquel séquito de equites, que aparece en la fase plena, que pudiera estar constituido por individuos ligados a los linajes dominantes, bien por lazos de parentesco, bien por lazos de dependencia militar. Lo cual no excluye una tercera posibilidad, que se dieran las dos situaciones, al mismo tiempo. No obstante, el profesor M. Torelli, en una de sus intervenciones en el Coloquio «Iconografía ibérica e itálica: pro- puestas de interpretación y de lectura», celebrado en Roma, en noviembre de 1993, sugeria la posibilidad de analizar este tipo de relaciones, a partir de los denominados silicernia, de la necrópolis de Los Villares (Blánquez, J., 1990).

Un caso semejante pudieran ser las «tumbas principescas» 200 y 277 de El Cigarralejo (Cuadrado, E., 1987), por ser contemporáneas y datarse ambas en el segundo cuarto del siglo IV a.C. (ver Santos Velasco, J. A., 1989). ¿Son las tumbas de los más altos representantes de dos linajes aristocráticos diferentes, o uno de ellos representa un linaje ligado al otro, por lazos de dependencia?

\section{CONSIDERACIONES FINALES}

Después de revisar estos datos, el siguiente paso seria tratar de definir cada período del iberismo, desde el punto de vista de su estructura social. A. Ruiz Rodriguez ha propuesto para la Andalucía oriental un modelo según el cual:

«La fase antigua se caracteriza por un sistema monárquico de carácter parental que, con la caida del mundo tartésico, a fines del siglo vi a.C., entra en crisis (destrucción del monumento de Porcuna hacia 500 a.C.). En el transcurso del siglo $v$ a.C. se da paso a un modelo atomizado o nuclearizado de carácter aristocrático, que tan sólo pretende asegurar el papel de las aristocracias locales, a partir de un sistema de servidumbre clientelar, que destruye los antiguos sistemas parentales vigentes. Más tarde, la crisis del siglo Iv a.C. es exponente del agotamiento del sistema nuclearizado y parece actuar en la definición de nuevos grupos étnicos (oretanos, bastetanos). Se consuma en esta nueva fase un reencuentro con la monarquía, pero ésta se presenta ahora con la crudeza del sistema aristocrático y fundamentada en la propiedad del territorio" (Ruiz, A., 1990, 20).

Muy probablemente el modelo de la cuenca del Segura sea semejante, a grandes rasgos, a éste, aunque teniendo en cuenta matizaciones culturales y cronológicas. Si aceptamos la hipótesis de una estructura tribal desarrollada, para la fase antigua, un estadio de organización avanzado, inmediatamente previo al de la sociedad de clases, que se define en la fase plena, nos hallariamos ante una forma de organización centralizada suprafamiliar (como pueden sugerirnos los grandes monumentos tipo Pozo Moro), pero basada en comunidades, cuya base de cohesión es todavía el parentesco, en línea con lo que propuso, en su día, Dominguez Monedero, para la 
fase antigua (1984, 153), con la salvedad del uso del concepto de jefatura ${ }^{15}$.

Durante la fase plena, la consolidación de las aristocracias locales y la sustitución del parentesco por relaciones sociales de clase entrarían en contradicción con el antiguo poder centralizado de la tribu, que se rompería atomizándose en una pluralidad de poderes comarcales, marcados por una cierta isonomia entre linajes aristocráticos. En concordancia con la propuesta de Ruiz Rodriguez y Molinos (1993). para el Alto Guadalquivir: un modelo aristocrático plurinuclear.

No estamos ante formas de estado, territorial, centralizado y definido política y jurídicamente, sino atomizado, pero, lo esencial, de naturaleza de clase, donde la superestructura politica está aún sin desarrollar, o lo está incipientemente. La aparición del estado se traslada asi a la formación de una aristocracia y a la concentración del poder en manos de ciertos individuos que encarnan el poder general (Godelier, M., 1980, 611).

En época ibérica, han surgido dos de los elementos básicos de una organización estatal: las clases sociales y la coerción.

Al primer componente ya se han dedicado las páginas anteriores. Sobre el segundo, la coerción, únicamente señalar que se deduce por la importancia del armamento en las necrópolis, los asentamientos fortificados, y las destrucciones de poblados y necrópolis ${ }^{16}$.

Más tarde, tras superarse la crisis de fines del siglo IV a.C. pudo volverse a poderes regionales, centrados en las ciudades homónimas de sus respectivos pueblos (Basti/bastetanos, Oretum/oretanos), como sugiere Ruiz Rodriguez en el Alto Guadalquivir (1990, 20). En la zona del Segura pudo darse un fenómeno análogo, en torno a Ilici, aunque nos faltan todavía más datos de campo para poder sustentar firmemente esta hipótesis; lo que no impide exponerla a título preliminar (ver Santos Velasco, 1992) ${ }^{17}$.

\footnotetext{
${ }^{15}$ En la actualidad parece más apropiado volver a las antigua denominacion de tribu, descartando la de jefatura, cuyo contenido ha sido objeto de critica, por autores como F. Nocete (1984) y D. Plácido, J. Alvar y C. González Wagner (1991). Ver también Gregory (1984).

in Sobre estas últimas se han enunciado multitud de hipótesis. Recientemente Chapa Brunet (1993) advierte que, al menos, parte de los monumentos destruidos no lo fueron por acciones violentas, sino porque estaban en desuso, desde tiempo atrás. Este problema es muy complejo y seguramente muchas de las hipótesis formuladas no son excluyentes, sino complementarias.

${ }^{17}$ A este respecto, destacar que Ruiz Rodríguez y Molinos $(1993,268)$ proponen la definición de la unidad territorial contestana sobre la base de la dispersión del llamado estilo de Elche de la pintura vascular.
}

Para concluir, tan sólo volver a señalar que el criterio utilizado para la caracterización de la sociedad ibérica, al menos en las fases plena y baja, como una sociedad dotada de formas estatales arcaicas, ha sido la existencia de clases sociales antagónicas. Desde luego, hay que dejar el debate abierto puesto que, incluso desde una óptica materialista, cabe plantearse la aparición del estado únicamente cuando éste se define politicamente y no sólo cuando lo hace su estructura social. En este sentido, habria que llamar la atención sobre la necesidad de la toma de postura teórica del arqueólogo-historiador que trata estos temas, ya que no estamos ante un debate de materiales arqueológicos tangibles, sino ante una discusión dotada de una fuerte carga politica e ideológica. Con la falta de una definición clara se corre el peligro de caer en un afán "modernizador» que no es sino un espejismo, ya que estos postulados tienen una larga trayectoria historiográfica:

«El estado nace de la necesidad de refrenar los antagonismos de clases y también en el seno del conflicto de esas clases» (Engels, F., 1884, 1980, 197).

\section{REFERENCIAS BIBLIOGRÁFICAS}

ABAD, L. y SALA, F. (1993): El poblado ibérico de El Oral, S.I.P., Valencia.

d'Agostino, B. (1982): «L,ideologia funeraria nell,età dell ferro in Campania: Pontecagnano. Nascita di un potere di funzione stabile, en Gnoli y Vernant (eds.)", La mort, les morts dans les societés anciennes, Londres.

Almagro Gorbea, M. (1983): «Pozo Moro. Un monumento orientalizante, su contexto socio-cultural y sus paralelos en la arquitectura funeraria ibérica», Madrider Mitteilungen, 24.

- (1992): Las necrópolis ibéricas en su contexto mediterráneo, Congreso de Arqueología Ibérica: las necrópolis, Madrid.

ARANEGUI, C. et al. (1992): "La necrópolis de Cabezo Lucero (Guardamar, Alicante)", Congreso de Arqueología Ibérica: las necrópolis, Madrid.

ARNOLD, B. (1991): "The material culture of social structure: rank and status in early Iron Age Europe», Cambridge, Mass.

BARTOLONI, G. (1990): La cultura villanoviana, Roma.

BLÁNQUEZ, J. (1990): La formación del mundo ibérico del sureste de la meseta, Albacete.

- (1992): Las necrópolis ibéricas en el sureste de la meseta, Congreso de Arqueologia ibérica: las necrópolis, Madrid. 
BRoMI.1. I. y PtrsHITS. A. (1985): «tingels and contemporary problems concerning the history of primitive society". Sovier Anthropologi and Archaeologl: XXIII, 4. N.Y.

(UADRAD(), 1: (1987): La mecropolis iherica de E:I (igarralejo (1/ula, Murcia), B.P.H., Madrid.

CHAPA BRINH, T. (1993): "La destrucción de la escultura funeraria iberican. Trahajos de Prehistoria, 50, Madrid.

CIIAPA, T. y PI:RI:IRA, J. (1991): "EI oro elemento de prestigio en época ibérican, Archivo Español de Arqueologia, 64, Madrid.

- (1992): La necrópolis de Castellones de Ceal (Hinojares, Jaén). Congreso de Arqueologia Ihérica: las necropolis, Madrid.

DOMINGiUtz MONFDtRO, A. (1984): "La escultura animalistica ibérica contestana como exponente del proceso de helenización del territorio", Arqueologia espacial, IV, Teruel.

- (1986): en T. Chapa, Influjos griegos en la escultura ibérica zoomorfa. Madrid.

ENGiELS, F. (1884, 1980): El origen de la familia. la propiedad privada y el estado, Méjico.

GARCIA CANO, J. M. (1992): «Las necrópolis ibéricas en Murcia", Congreso de Arqueologia Ihérica: las necropolis, Madrid.

GODELIFR, M. (1980): «Process of the formation diversity and bases of the state", en Int. Soc. Sci. J., XXXII, 4 .

GONZÁLtZ WAGNER, C. (1990): «La Jefatura como instrumento de análisis del historiador. Cuestiones teóricas y metodológicas», en Espacio y organización social, Madrid.

GREGORY, C. A. (1984): «The economy and kinship: a critical examination of some of the ideas of Marx and Levi-Strauss, en Spriggs (ed.)", Marxist perspectives in Archaeologv, Cambridge.

HARNECKER, M. (1973): Los conceptos elementales del materialismo histórico, Madrid.

MONRAVAL, M. (1992): La necrópolis ibérica de El Molar (Alicante), Alicante.

NEgUeRUELA, I. (1990): Los monumentos escultóricos ibéricos del Cerrillo Blanco de Porcuna (Jaén), Madrid.

NOCETE, F. (1984): “Jefaturas y territorio: una revi= sión crítica", Cuadernos de Prehistoria y Arqueologia de la Universidad de Granada, 9, Granada.
(1989): El espacio de la coercion. La transicion al estade en las campiñas del Alto Guadalquivir. B.A.R., 492, Cambridge.

PAcil, V. et al. (1987): Diez años de excavaciones en Coimbra del Barrancos Ancho (.Jumilla, Murcia), Murcia.

Pl.icio), D. et al. (1991): La formación de los estados en el Mediterraneo occidental, Madrid.

PRI:SI:D), F. (1982): La necropolis de Baza, Madrid.

PRIETO ARCINII:(iA, A. (1978): "La devotio ibérica como forma de dependencia en la Hispania prerromana". Memorias de Historia Antigua, 2, Oviedo.

QUF:SADA, F. (1986-87): «El armamento de la necrópolis ibérica de El Cabecico del Tesoro (Murcia)", Cuadernos de Prehistoria y Arqueologia de la U.A.M., 13-14, Madrid.

- (1989): Armamento, guerra y sociedad en la necropolis ihérica de El Cabecico del Tesoro (Murcia), B.A.R., 502, Cambridge.

RUANO, E. (1987): Escultura figurada en piedra de época ibérica, Madrid.

Ruiz, A. (1990): El contexto histórico cultural del conjunto de Porcuna. Escultura ibérica en el Museo de Jaén, Jaén.

RUIZ, A. y MOLıNos, M. (1993): Los iberos: análisis arqueológico de un proceso histórico, Barcelona.

RUIZ, A. et al. (1992): "Las necrópolis ibéricas en la Alta Andalucian, Congreso de Arqueologia ibérica: las necrópolis, Madrid.

SÁnchez Meseguer, J. y Quesada, F, (1992): «La necrópolis ibérica del Cabecico del Tesoro (Verdolay, Murcia)", Congreso de Arqueologia Ihérica: las necrópolis, Madrid.

SANTOS VELASCO, J. A. (1989): «Análisis social de la necrópolis de El Cigarralejo y otros contextos funerarios de su entorno", Archivo Español de Arqueologia, 62, Madrid.

- (1992): Territorio económico y politico del sur de la Contestania ibérica, Archivo Español de Arqueologia, 65, Madrid.

SERVICE, E. R. (1984): Los origenes del estado y la civilización, Madrid.

Solinas, P. G. (1976-77): «Note per la discussione metodologica sull, analisis economica della società primitiva), Dialoghi di Archeologia, IX-X, Roma.

TORELli, M. (1981): Storia degli etruschi, Roma. 